\title{
Eco Trash: Um jogo computacional para auxílio na educação ambiental
}

\author{
Jailson Alves ${ }^{1}$, Gabriel Martins Miranda ${ }^{1}$, Izaque Dadalto Marchetti Ferreira ${ }^{1}$, \\ Patricio Sante $^{1}$, Vanessa Battestin Nunes ${ }^{1}$, Rutinelli Fávero ${ }^{1}$ \\ ${ }^{1}$ Instituto Federal do Espírito Santo (Ifes) \\ Rodovia ES-010 - Km 6,5 - Manguinhos 29173-087 - Serra - ES - Brasil \\ jailson.89@hotmail.com, fgabrielmartinsmiranda, izaquedmf, \\ patricio.sante\}@gmail.com, \{vanessa, rutinelli\}@ifes.edu.br
}

\begin{abstract}
The pollution caused by garbage threatens life in the oceans. One way to minimize this problem is through programs such as selective collection. The most important piece in this process are the people, but often they are not aware of the problem. This paper presents the creation of an educational game about selective collection called Eco Trash, which aims to establish an ecological subject, aiming to support the construction of an environmental conscience. The evaluation by a specialist in education indicated that the tool meets pedagogical requirements and pointed aspects to be improved.
\end{abstract}

Resumo. A poluição causada pelo lixo ameaça a vida nos oceanos. Uma das formas de minimizar esse problema é por meio de programas como os de coleta seletiva. A peça mais importante nesse processo são as pessoas, mas muitas vezes elas ainda não possuem as orientações necessárias. Esse trabalho propõe a criação de um jogo educativo sobre coleta seletiva, chamado Eco Trash, que visa colaborar na formação de um sujeito ecológico, objetivando apoiar a construção de uma consciência ambiental. A avaliação por uma especialista da área educacional apontou que a ferramenta atende a requisitos pedagógicos fundamentais e apontou aspectos a serem melhorados.

\section{Introdução}

Os resíduos lançados ou deixados no mar causam muitos prejuízos ao ambiente marinho e prejudicam os seres vivos que fazem parte desse ecossistema. Um estudo da United Nations Evironment Program (UNEP), em 2006, estimou que havia no oceano 46 mil pedaços de plástico a cada uma milha quadrada - cerca de $18.000 / \mathrm{km}^{2}$ [Allsopp 2006].

Além da necessidade de medidas relacionadas com políticas específicas que envolvam governos e empresas, os impactos negativos poderiam ser minimizados com uma maior participação social nos programas de coleta seletiva e reciclagem de lixo, que além de gerar renda também podem diminuir a poluição dos solos, rios, mares e oceanos. No Brasil, apesar de sua grande importância social, a coleta seletiva só existe em 443 cidades (8\% do total) [CEMPRE 2010]. E algumas vezes não se obtém o sucesso desejado porque a falta de informação é o maior problema enfrentado.

Uma pesquisa exploratória inicial ${ }^{1}$ relacionada à coleta seletiva de lixo, realizada com 15 alunos do Curso de Bacharelado em Sistemas de Informação do Instituto Federal do Espírito Santo (Ifes) e um professor, mostrou que esse problema ocorre

\footnotetext{
${ }^{1}$ A pesquisa está disponível em: https://docs.google.com/file/d/0Bwuoj0AuPAhdWU5JRXI4REVYNms
} 
independente do nível de escolaridade ou classe social. Nove dos 16 respondentes (56\%) afirmaram já ter participado de alguma palestra sobre coleta seletiva há menos de dois anos. Porém, ainda assim, os resultados não foram bons. Das cinco perguntas sobre o local correto de armazenar determinados lixos 50\% acertaram para folhas de caderno, $37 \%$ acertaram sobre restos de comida, $25 \%$ sobre guardanapo usado. Porém, todos erraram os outros dois itens (estilhaços de copos de vidro e copo descartável).

Acreditamos que o principal fator para o sucesso de projetos de coleta seletiva é a participação das pessoas e ações educativas são necessárias para tal. Assim, o presente trabalho teve como objetivo principal desenvolver um jogo computacional para colaborar com a formação processual do "sujeito ecológico" através da coleta seletiva, de forma lúdica e com aberta possibilidade para vários tipos de públicos utilizarem.

\section{Educação Ambiental e a Coleta Seletiva}

As práticas de Educação Ambiental visam construir com os indivíduos conceitos sobre a realidade ambiental e mostrar o papel da sociedade nela. Compreendemos ser essa formação a do sujeito ecológico: "O sujeito ecológico é incorporado pelos indivíduos ou pessoas que adotam uma orientação ecológica em suas vidas" [Carvalho 2008 p.29].

Um dos focos da Educação Ambiental é a problemática do lixo, procurando incorporar práticas sobre o uso responsável dos recursos naturais, visando provocar mudanças de atitudes nas pessoas e o consumo sustentável [SEMA 2011]. Como afirmam Silva e Joia (2008), “[...] Para o sucesso de um projeto de coleta seletiva é necessária a mobilização da população através da prática de Educação Ambiental”.

A Coleta Seletiva se constitui numa prática para tratar o lixo de forma correta, onde o lixo é separado para ser recuperado, reutilizado ou reciclado, trazendo o material de volta para o ciclo de produção. No Brasil, há uma legislação sobre coleta seletiva e a Resolução CONAMA n 275 (BRASIL 2001) para tratar o padrão de cores das lixeiras.

\section{Jogos Educacionais}

Pensando em desenvolver ferramentas de aprendizagem que facilitem e despertem o interesse das pessoas em aprender mais no que se refere à Educação Ambiental, os jogos educativos por meio de computadores podem ser extremamente eficientes, já que podem gerar curiosidade e contribuir para o aprendizado. De acordo com Pereira e Passos (2012 p.308), "[...] os jogos didáticos proporcionam interatividade, o que torna o processo de ensino aprendizagem mais eficiente, atrativo e significativo".

Albernaz (2008) elenca alguns aspectos que devem ser considerados no processo de criação de um jogo educacional de qualidade, dando destaque não apenas aos requisitos não funcionais, comumente analisados no desenvolvimento de sistemas computacionais, mas também aos requisitos pedagógicos, muitas vezes esquecidos ou pouco considerados em diversos softwares educativos.

Contudo, mesmo sendo uma ferramenta capaz de melhorar a educação, no período de 2001 a 2010 nos anais do Simpósio Brasileiro de Informática na Educação (SBIE), houve uma carência de publicações envolvendo jogos, apenas 5,4\% do número total publicado nos anais [Pietruchinski 2011]. 


\section{Metodologia}

Para o desenvolvimento desse jogo educativo, inicialmente foi realizada uma pesquisa bibliográfica sobre os temas de educação ambiental, coleta seletiva e jogos educativos. A seguir, foi feita uma pesquisa exploratória inicial sobre coleta seletiva, obtendo-se retorno de 15 alunos do Curso de Bacharelado em Sistemas de Informação do Ifes e de um professor, visando identificar seu grau de conhecimento sobre o tema.

O passo seguinte foi a construção do jogo, em um modelo cascata, realizando-se as atividades: Planejamento, Análise, Projeto, Implementação e Testes. Por fim, o jogo foi analisado por uma especialista da área educativa com o objetivo de validar se o jogo atingiria os objetivos esperados e de apontar sugestões de melhoria.

\section{O jogo Eco Trash}

Quando o jogo inicia, é apresentada uma tela com imagens relacionadas à poluição no oceano como forma de deixar subentendido o propósito do jogo e, em seguida, a tela do menu principal (Figura 1), em que o jogador poderá: iniciar o jogo, escolher (em "opções”) o nível de dificuldade (fácil, médio, difícil), visualizar recordes e sair.

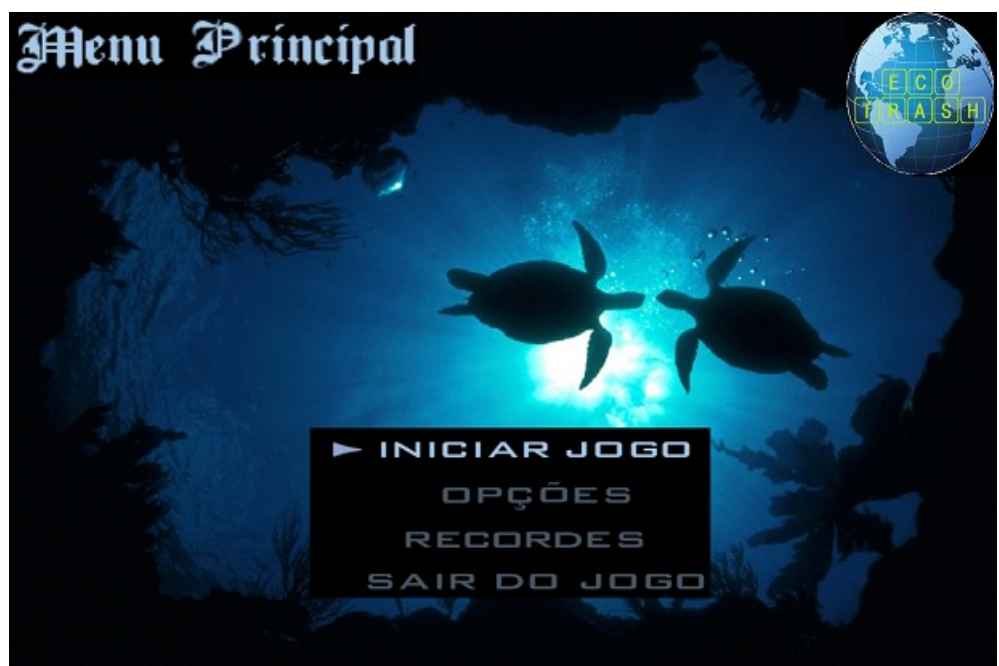

Figura 1. Tela Inicial do Eco Trash

Após iniciar o jogo, será exibida a tela da Figura 2, com animais passando no mar, lixeiras nas cores do padrão da coleta seletiva, e lixos caindo da parte de cima.

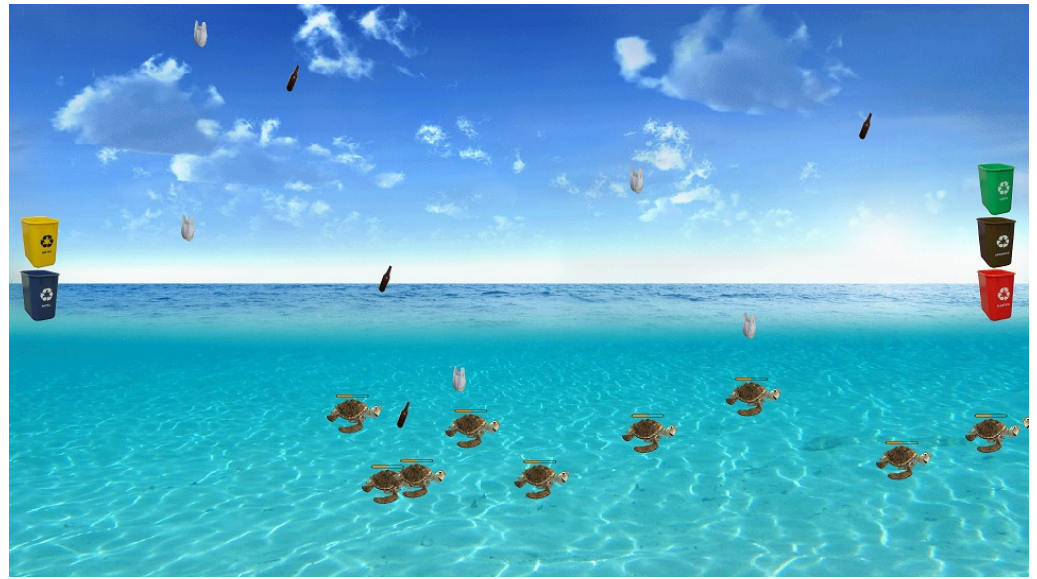

Figura 2. Tela do jogo Eco Trash. 
A primeira fase do jogo foi construída com o objetivo de ensinar a jogar. Quando o jogador clicar em um lixo, a lixeira correta ganhará destaque. Haverá uma opção "skip" que permite ao jogador pular essa fase introdutória.

$\mathrm{Na}$ fase inicial, cairá do topo da tela 30 lixos (aumentando 10 em cada nova fase). No mar, haverá animais passando, com 50 pontos de vida cada. O jogador não deve deixar que ao animal coma o lixo, evitando que este caia no mar. Para isso, deverá clicar sobre o lixo e arrastá-lo até a lixeira apropriada. Por exemplo: papéis na lixeira azul, garrafas de vidro na verde etc. Se o jogador errar a lixeira, o lixo continuará a cair. Se o jogador acertar, aparecerá um ' $\mathrm{V}$ ' verde, do tamanho da lixeira e a pontuação (mostrada no canto superior direito da tela) será incrementada. Caso o lixo caia no mar e o animal passe por cima, ele irá comer o lixo e perderá pontos de vida (10 pontos no nível fácil, 20 no normal e 30 no difícil), visualmente mostrado por meio de uma barra acima do animal. Quando o animal perder todos os pontos de vida (chegar a 0), ele morrerá. A fase será concluída quando não houver mais lixos na tela e ainda restarem animais vivos. $\mathrm{O}$ jogador, então, passará para a próxima fase. Ele perderá o jogo quando todos os animais morrerem. O jogo possui 10 fases, com quantidades de lixo diferentes.

Busca-se levar o jogador a aprender um pouco mais sobre coleta seletiva por meio de: informação, ação e feedbacks. Quanto ao caráter informativo, na mudança de uma fase para outra serão exibidas informações sobre o impacto da poluição no oceano. A ação ocorre quando o jogador interage com o jogo. Já os feedbacks mostram ao jogador se sua ação foi adequada ou não. Por exemplo, quando ele joga um objeto na lixeira correta, ganha pontos, motivando-o e o informando do sucesso de sua ação. Porém, se joga em uma lixeira incorreta, o lixo cai na água e, posteriormente, quando o animal comer o lixo, irá perder pontos de vida, e quando perder todos os pontos, morrerá, mostrando que a opção selecionada não foi adequada e, também, alertando sobre os possíveis impactos de suas atitudes, auxiliando na conscientização ambiental.

\section{Avaliação por um especialista}

Para a validação do jogo Eco Trash, desenvolvemos um questionário baseado nos trabalhos [Albernaz 2008] e [Nobre et al. 2011], destacando requisitos de usabilidade e pedagógicos e tendo como possíveis respostas: atende plenamente, atende parcialmente, não atende e não se aplica. Além disso, foi deixado um espaço para o avaliador fazer suas considerações e sugestões para melhorias do jogo.

A avaliação foi realizada por uma professora que também já atuou como pedagoga, tendo larga experiência no ensino infantil, fundamental e superior. Com relação aos requisitos de usabilidade, a avaliadora considerou que quatro requisitos eram plenamente atendidos (facilidade de uso, possibilidade de repetição, regras coerentes, nível de concentração exigido), outros quatro eram atendidos parcialmente (linguagem, atratividade, ludicidade, incentivo à autonomia e envolvimento), apenas um não atendia (permitir vários caminhos de solução). Porém, com relação aos requisitos pedagógicos, ela considerou que todos atendiam a contento (conteúdo coerente, graus de dificuldade variáveis, facilita o aprendizado, oferece feedbacks construtivos, é dado incentivo (pontuação) ao se atingir certos marcos a fim de motivar, faz referência ao universo cotidiano em uma perspectiva de formação e de cidadania. Essa avaliação foi muito positiva no sentido de mostrar que o jogo tem potencial para atingir seu maior objetivo que é a consciência ambiental, por meio do seu caráter educativo. 


\section{Conclusões e Trabalhos Futuros}

O presente artigo mostrou o jogo educativo Eco Trash, construído com a finalidade de auxiliar no sucesso de programas em prol do meio ambiente, no caso o de coleta seletiva, por meio da formação de um sujeito ecológico.

A avaliação de uma especialista da área pedagógica mostrou que o jogo atende aos requisitos pedagógicos e, assim, tem boa possibilidade de conseguir atingir seus objetivos. Por outro lado, alguns requisitos de usabilidade precisam ser melhor tratados.

Apenas algumas partes do jogo foram implementadas. Assim, em trabalhos futuros, deverão ser acrescentadas outras funcionalidades. Sugere-se, ainda, avaliar o jogo pelos seus usuários reais, definindo procedimentos metodológicos para coleta e análise dos dados, visando identificar as dificuldades de uso, os aprendizados obtidos, se os jogadores se mostraram motivados, se os feedbacks foram adequados, entre outros.

\section{Referências}

Albernaz, Jussara M. (2008). "Jogo computacional como desencadeador de aprendizagem matemática nas series iniciais do ensino fundamental: Sua avaliação por professors e alunos". Universidade Federal do Espírito Santo - UFES.

BRASIL, (2001), Ministério do Meio Ambiente. "Resolução CONAMA no 275, de 25 de abril de 2001", http://www.mma.gov.br/port/conama/legiabre.cfm?codlegi=273.

Carvalho, Isabel C. M. (2008), "Subjetividade e Sujeito Ecológico: contribuições da psicologia para a educação ambiental".

CEMPRE - Compromisso Empresarial para Reciclagem. (2010), "CICLOSOFT indica necessidade de novo impulso para a coleta seletiva", http://www.cempre.org.br/ci_2010-0708_reciclando.php, Julho.

Nobre, I. A. M., Rosário, K., Siqueira, A., Nascimento, E. L. (2011), "Consciência Ambiental: Objeto de Aprendizagem como Apoio ao Ensino de Meio Ambiente". In: $17^{\circ}$ Workshop de Informática na Escola (WEI), Aracaju, SE. Anais do XXII SBIE XVII WIE. , 2011.v.1. p.194 - 203.

Pereira, D. C. e Passos, M. L. S. (2012), "Jogos Educativos: Uma Análise Pedagógica para Apoio à Disciplina de Português" In FÁVERO, R. P., et al. (2012), "Coletânea de Artigos sobre INFORMÁTICA NA EDUCAÇÃO: Construções em Curso", Espírito Santo: CEAD.

Pietruchinski, M. H., et al. (2011), "Os jogos educativos no contexto do SBIE: uma revisão sistemática de Literatura", XXII Simpósio Brasileiro de Informática na Educação.

SEMA - Secretaria de Estado do Meio Ambiente. (2011), "Guia Pedagógico do Lixo". 12 ed. São Paulo.

Silva, M. S. F. e Joia, P. R. (2008), "Educação Ambiental: A participação da comunidade na coleta seletiva de resíduos sólidos". Revista Eletrônica da Associação dos Geógrafos Brasileiros. 